\title{
CALVO CABALLERO, Pilar, Beneficencia y ciudad. La Casa de Beneficen- cia de Valladolid (1818-2018), Editorial Maxtor, Valladolid, 2018, 406 pp.
}

Con este libro, la autora aborda el estudio de la decana de la beneficencia vallisoletana y completa la red de sus asociaciones de beneficencia privada durante los siglos XIX-XXI, piezas pendientes en esta consolidada línea de investigación de la Universidad de Valladolid. Por ser esta Casa de Beneficencia la única superviviente nacional, su investigación la enmarca en la comparación con sus homónimas, que confirma que esta fórmula de interior y periferia, lejos de espontánea, nació empeñado intento de superar los fallidos proyectos ilustrados que eslabonaron hospicios, casas de misericordia y de caridad. La vallisoletana refuerza desde julio de 1818 este proyecto benéfico que inauguran en marzo sus homónimas de Valencia y Palencia, de las que toma el nombre, y reproducirán otras levantinas nacidas a imagen de la valenciana. Pero desde este primer rodaje, la vallisoletana ya apunta coincidencias y diferencias.

Todas ellas nacen de manos de los Amigos del País y, aunque decidido, fueron proyecto en construcción. Vallisoletana y valenciana comparten su impulso bajo los generales O'Donnell (Carlos y José, de los que hay pruebas de intercambio de experiencias) y su conexión con la Corona. A diferencia de sus homónimas, la vallisoletana sobrevivirá sin interrupción y, aunque se pretende dique a la miseria y a sus efectos sobre la salud pública, difiere de la valenciana que ambicionó resolver el paro de las crisis de trabajo. Esta mira le apegaría más a viejas soluciones a diferencia de la vallisoletana, que rompe con los dos pilares ilustrados que levantaron los asilos hasta ese momento. Según la autora, los rompe por fallidos: el asilo convertido en fábrica de trabajo para pobres, en que sus homónimas también repiten el fracaso, y la transversalidad de los asistidos (mendigos oriundos y forasteros, pobres de todo sexo y edad). La vallisoletana se ofrece a sus convecinos ancianos y menestrales imposibilitados para el trabajo, excluye a los niños por haber Casa de Misericordia y si se vio obligada a asistir a los forasteros, los descartará en cuanto surjan nuevas asociaciones de beneficencia privada.

Trayectoria sin discontinuidad y ruptura de ambos pilares ilustrados cifran la singularidad de la vallisoletana, que la autora atribuye a la que sería su clave y principal diferencia con sus homónimas: la acertada elección de una directiva comprometida. Directiva que es cabeza de la Sociedad Económica de Amigos del País y que suma a vecinos que igualan en empeño a los O'Donnell. Son una elite de la Iglesia avezada en materia benéfica y de la Universidad, comercio y autoridad política; el peso recae en tres hombres de Iglesia que erigirán la Casa de Beneficencia y la sostendrán en las ausencias o no de los generales, de tibio compromiso los sucesores de los O’Donnell, y en el tránsito del Antiguo Régimen al Liberalismo. Fallecidos esos tres hombres a la altura de los años cuarenta, el testigo lo recoge una directiva plenamente burguesa. Esta imprimirá desde entonces 
Reseñas de libros

sus valores de orden y trabajo en la Casa, además de continuar con otra de sus señas: su buen gobierno económico. Por este fue reconocida por instituciones locales y generales del Reino, apreciada por el vecindario que la sigue confiando su óbolo y explica, según la autora, que la Casa de Beneficencia de Valladolid sea la única que salve su autonomía, entre sus homónimas, de las Leyes de Beneficencia de 1822 y 1849 que la estatalizan. Y en fin, ese buen gobierno económico explica que Concepción Arenal la ponga por modelo de lo que deberían ser las asociaciones benéficas.

Con el enfoque comparativo, cabe destacar el más novedoso análisis del binomio directivos/asistidos en términos de beneficencia. En la confrontación entre orden y desorden, la autora rebate los planteamientos foucaultianos del asilo como gran encierro para vigilar y castigar, pues fueron mayoritarias las solicitudes pidiendo entrar en la Casa voluntariamente. Las fugas y reentradas de asilados expulsados probarían que el orden en la Casa no lo marcaron solo los directivos, sino que los asistidos no fueron pasivos y resisten en sus hábitos de embriaguez, escándalo, amotinamiento y robo. Los directivos, el mayordomo y las Hijas de la Caridad serán el blanco de los insultos de algunos asilados, ni se librarán de su violencia sus propios iguales.

La Casa fue así espacio de pugna entre hábitos populares y valores burgueses. También hogar para la mayoría que entra voluntaria y que contribuye a sostener la vida cotidiana de la Casa, con su trabajo dentro y fuera de ella durante el primer siglo y medio. Una mayoría tutelada por el mayordomo y desde 1870, coincidiendo con su homónima valenciana, por las Hijas de la Caridad. Estas fueron el nervio de ambas Casas, cuyas iniciativas comparten, y no es su única convergencia. En el último cuarto del siglo XIX la valenciana se especializa como las levantinas en hospicio y la vallisoletana, sin perder su mira por ancianos e imposibilitados menestrales, suma unas escuelas. Orientación por la infancia reforzada por las mandas del vecindario vallisoletano que la directiva consolida, acogiendo en la Casa, las Fundaciones Asilo de Nuestra Señora del Carmen (1944), que será hospicio para las niñas del Tribunal de Menores, y Escuela Santa Florentina (1959), que amplió la oferta educativa de sus escuelas. La legislación que aboca al cierre de los hospicios desde los años ochenta del siglo XX es la puntilla de la Casa valenciana y del Asilo del Carmen de la vallisoletana. Pero esta sobrevive al transformar su mira por la ancianidad en residencia de la tercera edad desde los años sesenta, y conservar su Colegio de la Milagrosa y Santa Florentina respaldado por la Fundación Santa Florentina. Decana vallisoletana y única superviviente nacional de su título, esta Casa de Beneficencia ha trazado más que afinidades y diferencias con sus homónimas, puede seguirse en este libro que su historia es indisociable de la ciudad, de la sociedad vallisoletana y de sus transformaciones durante los últimos dos siglos.

Juan Antonio Cano García 